\title{
Synthesis, Characterization and Catalytic Activity of a Cobalt Catalyst: Silica-Supported, bis(1,5-diphenyl-1,3,5-pentanetrionato)dicobalt(II) [ $\left.\mathrm{Co}_{2}(\mathrm{dba})_{2}\right]$
}

\author{
S. A. Ranaweera ${ }^{\mathrm{a}, \mathrm{d}}$, M. D. Rowe ${ }^{\mathrm{b}}$, K. B. Walters ${ }^{\mathrm{b}}$, W. P. Henry ${ }^{\mathrm{a} \dagger}$, M. G. White ${ }^{\mathrm{b} *}$, \\ J. M. Rodriguez ${ }^{\mathrm{c}}$ \\ ${ }^{a}$ Department of Chemistry, Mississippi State University, Mississippi State, MS 39762, USA \\ ${ }^{b}$ Dave C. Swalm School of Chemical Engineering, Mississippi State University, Mississippi \\ State, MS 39762, USA \\ ${ }^{c}$ Mississippi State Chemical Laboratory, Mississippi State University, Mississippi State, MS \\ 39762, USA \\ ${ }^{\mathrm{d}}$ Faculty of Science, University of Ruhuna, Matara, Sri Lanka \\ $\dagger$ Deceased \\ *Corresponding author: (M. G. White) Dave C. Swalm School of Chemical Engineering, \\ Mississippi State University, Mississippi State, MS 39762, USA white@che.msstate.edu
}

\begin{abstract}
Models of silica supported cobalt catalysts were formed by decorating the surface of Cab-O-Sil with the dinuclear cobalt complex, bis(1,5-diphenyl-1,3,5-pentanetrionato) dicobalt(II), $\left[\mathrm{Co}_{2}(\mathrm{dba})_{2}\right]$. To confirm the formation of a monolayer and multilayer of the complex on Cab-OSil, various loadings of $\left[\mathrm{Co}_{2}(\mathrm{dba})_{2}\right]$ were combined with $\mathrm{Cab}-\mathrm{O}-\mathrm{Sil}$ by batch impregnation. The supported samples were characterized by elemental analysis, DRIFTS, and TGA to show that the $\mathrm{Co}_{2}(\mathrm{dba})_{2}$ complex was adsorbed on the silica surface intact and DRIFTS confirmed the loading of the $\mathrm{Co}_{2}(\mathrm{dba})_{2}$ as a monolayer on the Cab-O-Sil up to a loading < $2.09 \mathrm{wt} \% \mathrm{Co}$. This experimental monolayer loading confirmed the predicted loading ( $2.06 \mathrm{wt} \%$ Co metal) based on the surface area of the support, $200 \mathrm{~m}^{2} / \mathrm{g}$, and the footprint area of the complex $\left(1.866 \mathrm{~nm}^{2}\right)$. When this precatalyst was decomposed in air and reduced in hydrogen, the morphology of the resulting particles depended upon the initial disposition of the metal complex on the support. Monolayer films of the metal complex decomposed into metal or metal oxide particles which are too small to give XRD reflections ( $2.09 \mathrm{wt} \% \mathrm{Co}$ ); whereas, catalyst derived from a multilayer film (4.1 wt\% Co) showed large metal particles developing a very sharp XRD reflection from the $\mathrm{Co}(111)$ index. Both catalysts were active for the Fischer-Trøpsch reaction at $350^{\circ} \mathrm{C}$ with the catalyst derived from the multilayers of complex showing an activity, as characterized by first order rates constants, about 33 times that of the catalyst derived from a monolayer of the complex:71.4 vs 2.16 (mol Co-hour) ${ }^{-1}$. The selectivity to liquid hydrocarbons showed a remarkably narrow distribution of molecular weights, comprised of mainly iso- and cycloalkanes having 6-8 carbons.
\end{abstract}

Keywords: Batch impregnation; Bis(1,5-diphenyl-1,3,5-pentanetrionato)dicobalt(II); Silica supported; Dicobalt; Fischer-Trøpsch 


\section{Introduction}

The synthesis and design of organic-inorganic hybrid materials have attracted much attention [1-4]. These materials have potential for applications in gas storage, catalysis, supported catalysis, luminescence, magnetism and electrochemical activity [5-13].

Various supported cobalt complexes have been studied as catalysts for the Fisher-Tropsch (FT) reactions after various activation methods. Furthermore, supported cobalt catalysts have, also, been studied for the carbon dioxide reforming of methane [14], ethene hydroformylation [15], hydrogenation of aromatics [16-18], and selective hydrogenation of aldehyde groups in $\alpha, \beta$ unsaturated aldehydes [19].

Cobalt-supported catalysts show excellent activity and selectivity for FT synthesis and they have several advantages over other metal based catalysts. Cobalt catalysts demonstrate a high selectivity for the formation of long chain hydrocarbons, low water-gas shift activity, low olefin selectivity, and low oxygenate selectivity [12, 20-23]. It has been found that supported cobalt catalysts are more resistant to attrition than supported iron catalysts. Knowledge of the active site(s) for cobalt catalysts is important when designing new catalysts for FT synthesis. Evidence has been found for the existence of cobalt metal particles before, during, and after FT synthesis [24-28]. As a result, it is generally believed that supported cobalt metal particles are the active species for FT synthesis. Oxidation of cobalt particles to cobalt oxides such as $\mathrm{CoO}$ and $\mathrm{Co}_{3} \mathrm{O}_{4}$ leads to the deactivation of the catalyst $[25,29]$.

A variety of cobalt precursors have been used to prepare cobalt supported catalysts [29]. Model studies using cobalt, single crystal surfaces alone show FT synthesis activity [30]. The crystal surfaces of cobalt when exposed to syngas $\left(\mathrm{CO} / \mathrm{H}_{2}=2\right)$ at $493-573 \mathrm{~K}$ and $0.1 \mathrm{MPa}$ pressure [3033] produce methane as the major product and a small amount of long chain hydrocarbons. Based on these studies, the authors concluded that FT synthesis can be performed on cobalt metal surfaces; however the $\mathrm{CO}$ conversion was low compared to the supported cobalt catalysts [30, $31,33]$.

It has been shown that several factors influence the reactivity of the supported Co catalyst. These factors include the dispersion of the metal phase, the support [34-44], the cobalt precursor used in the preparation of the catalyst [39, 41, 45-48], the metal loading [18, 35, 49], the preparation method [35, 38, 41, 50-54], thermal treatment [39, 45, 55-58], and the reduction process [21, 59, $60]$.

The purpose of this investigation is to synthesize silica-supported, cobalt metal complexes bis(1,5-diphenyl-1,3,5-pentanetrionato)dicobalt(II), $\mathrm{Co}_{2}(\mathrm{dba})_{2}$, as catalysts. This metal complex will be arranged on the silica surface as either a monolayer or- a multilayer so as to elucidate the importance of the initial organization of these complexes upon the final physical and chemical properties.

The motivation for this work was synthesis of a silica-supported copper catalyst that was developed by decorating a silica support with layers of the dinuclear $\mathrm{Cu}$ complex: bis(1,5Diphenyl-1,3,5-pentanetrionato)dicopper(II) [61]. These Cu metal complexes showed a planar geometry that enhanced the contact of the triketonate ring systems with the silanol protons. 
Earlier work on beta-metal diketonate complexes [62] showed how such interactions between the silica surface and the diketonate rings systems resulted in a "strong" interaction of the metal complexes with the surface. The surface, silanol proton protonated the ketonate rings forming pentanedione which left the surface under mild heating at the monohydrate. The open orbital on the metal which formed when the ketonate group left was filled by the dative electron pair on the surface siloxide group. The resulting coordination bond formed the basis for the strong interaction of the metal complex fragment with the surface. Finally, we found that the bis dionato metal complexes, $\mathrm{M}_{2}$ (acac) $)_{2}$, (square planar) formed stronger interactions with the surface than the tris metal complexes, $\mathrm{M}_{3}(\mathrm{acac})_{3}$, (octahedral) because of steric hindrance of the (acac) ligand.

\section{Experimental}

\subsection{Chemicals}

Diethyl ether, methyl benzoate, sodium hydride monoglyme were purchased from SigmaAldrich. Acetone and methylene chloride were obtained from Fisher Scientific. $\mathrm{CoCl}_{2} \cdot 6 \mathrm{H}_{2} \mathrm{O}$ was obtained from Strem Chemicals. Cab-O-Sil (M-5 scintillation grade, $200 \mathrm{~m}^{2} / \mathrm{g}$ surface area) was purchased from ACROS Organics.

\subsection{Characterization techniques}

UV-vis spectra were recorded using a Shimadzu UV-2550 spectrometer over the 250-700 nm wavelength range. Measurements were performed in $1 \mathrm{~cm}$ quartz cuvettes with $\mathrm{CH}_{2} \mathrm{Cl}_{2}$ as the solvent.

Elemental analyses were performed by Galbraith Laboratories (Knoxville, Tennessee). All samples were analyzed for cobalt and carbon content.

A Thermo Nicolet 6700 spectrometer with a liquid nitrogen cooled MCT-A* detector controlled by Thermo Electron OMNIC software was used for collection of the DRIFTS spectra. Spectra were recorded with a $4 \mathrm{~cm}^{-1}$ resolution and averaged over 256 scans. Unsupported metal complexes were diluted in $\mathrm{KBr}$ powder $(2 \mathrm{wt} \%)$ and pure $\mathrm{KBr}$ was used for background scans. Supported metal complexes were also diluted in $\mathrm{KBr}(5 \mathrm{wt} \%)$ for infrared analysis and $5 \mathrm{wt} \%$ $\mathrm{Cab}-\mathrm{O}-\mathrm{Sil}$ in $\mathrm{KBr}$ was used to obtain the background. A minimum of 3 spectra per sample were collected to confirm sample homogeneity.

Thermal gravimetric analysis, TGA, was performed on 30-50 mg of metal complexes supported on Cab-O-Sil and unsupported metal complexes using a ThermoFisher Scientific Versa Therm ${ }^{\mathrm{TM}}$ TGA instrument in flowing helium. The temperature was increased from room temperature to $1000{ }^{\circ} \mathrm{C}$ at a rate of $5^{\circ} \mathrm{C}$ per minute.

Powder, X-ray Diffraction technique was used to characterize the silica-supported Co catalysts derived from the decomposition of precatatalysts having a monolayer film and multilayer film of $\mathrm{Co}_{2}(\mathrm{dba})_{2}$.

\subsection{Synthesis of ligands and metal complexes}




\subsubsection{1, 5-Diphenyl-1,3,5-pentanetrione $\left(\mathrm{H}_{2} \mathrm{dba}\right)$ [67]:}

The ligand was prepared using a procedure obtained from the literature and is described in the Electronic Supplementary Information (ESI).

2.3.2. $\mathrm{Bis}\left(1,5-\right.$ diphenyl-1,3,5-pentanetrionato)dicobalt(II) tetrahydrate $\mathrm{Co}_{2}(\mathrm{dba})_{2} \cdot 4 \mathrm{H}_{2} \mathrm{O}$ [63]: The procedure for preparing the metal complex is described in the ESI. It too is a procedure described in the literature. A structure of this complex is shown in Figure 1.

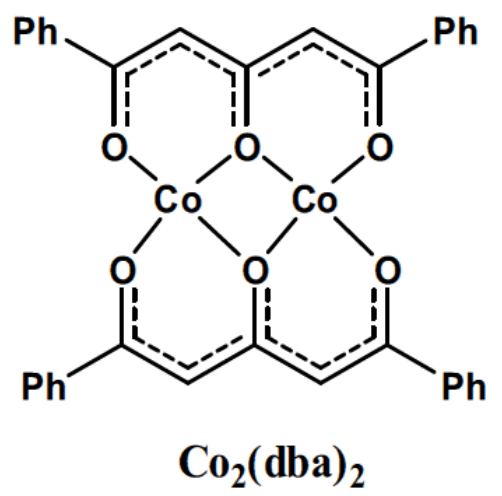

Figure 1: Structure of dicobalt complex used in this study; $\mathrm{Ph}=$ phenyl group.

\subsection{3. $\mathrm{Co}_{2}(\mathrm{dba})_{2} /$ silica Monolayer Precatalysts}

Approximately $1.0 \mathrm{~g}$ of $\mathrm{Co}_{2}(\mathrm{dba})_{2}$ was dissolved in $400 \mathrm{~mL}$ of $\mathrm{CH}_{2} \mathrm{Cl}_{2} .5 .0 \mathrm{~g}$ of Cab-O-Sil was then added and the solution was stirred for $24 \mathrm{~h}$, filtered, and washed with fresh $100 \mathrm{~mL}$ aliquots of $\mathrm{CH}_{2} \mathrm{Cl}_{2}$, and dried under reduced pressure for $4-6 \mathrm{~h}$. Then the catalyst was activated by heating in air at $400^{\circ} \mathrm{C}$ for $3 \mathrm{~h}$.

The same procedure was repeated using $2.0 \mathrm{~g}$ of $\mathrm{Co}_{2}(\mathrm{dba})_{2}$ and $10.0 \mathrm{~g}$ of Cab-O-Sil.

\subsection{4. $\mathrm{Co}_{2}(\mathrm{dba})_{2} /$ silica Multilayer Precatalysts}

$\mathrm{Co}_{2}(\mathrm{dba})_{2} /$ silica multilayer catalyst was prepared by utilizing $1.9 \mathrm{~g}$ of $\mathrm{Co}_{2}(\mathrm{dba})_{2}$ and $5.0 \mathrm{~g}$ of Cab-O-Sil. The reaction mixture was first stirred for $24 \mathrm{~h}$ and then the solvent was removed under reduced pressure to obtain $\mathrm{Co}_{2}(\mathrm{dba})_{2} /$ silica multilayer catalysts. Then the catalyst was activated by heating in air at $400{ }^{\circ} \mathrm{C}$ for $3 \mathrm{~h}$.

\subsubsection{Characterization of Monolayer and Multilayer Precatalysts}

We developed a protocol for characterizing these precatalysts so as to determine the metal loading at which a monolayer film of the complexes was formed [62]. The procedure includes: 1) estimating the size of the complex using molecular modeling software to determine its equilibrium structure; b) analyzing the precatalysts for the metal and carbon elemental composition, c) determining the weight change as a function of decomposition temperature; and d) examining the Infra Red (IR) spectrum of the supported metal complexes. The strategy is based upon the finding that the IR spectrum of some metal complexes is sensitive to hydrogen bonding arising from interactions between the ligands and the surface $\mathrm{OH}$ groups [62]. Task 1 is needed to compare with the experimental value of monolayer 
loading. Tasks 2 and 3 will confirm that the metal complex has not decomposed upon contacting the surface. Task 4 will identify those samples which show all complexes are resting on the surface of the support, i. e., a sample having less than or equal to monolayer loading. For example, the IR spectrum of $\mathrm{Cu}(\mathrm{acac})_{2}$ is missing one peak (overtone of $\gamma-\mathrm{CH}$, $1552 \mathrm{~cm}^{-1}$ ) when this complex is resting on silica. Recently, we extended this protocol to characterize films of metal complex analogous to the present study: bis(1,5-Diphenyl-1,3,5pentanetrionato)dicopper(II) [61]. This complex also showed an IR spectrum that is missing a peak when it contacts a silica surface.

Four $\mathrm{Co}_{2}(\mathrm{dba})_{2} /$ silica samples were prepared by stirring $200 \mathrm{~mL}$ solutions containing 40,60 , 80 , and $100 \mathrm{mg}$ of $\mathrm{Co}_{2}(\mathrm{dba})_{2}$ complex with $0.5 \mathrm{~g}$ of silica. Two $\mathrm{Co}_{2}(\mathrm{dba})_{2} /$ silica samples were prepared by stirring $80 \mathrm{mg}$ and $110 \mathrm{mg}$ of $\mathrm{Co}_{2}(\mathrm{dba})_{2}$ with $0.5 \mathrm{~g}$ of silica followed by completely evaporating the solvent slowly at room temperature to obtained multilayer films.

These catalysts were examined by elemental analysis, TGA thermal decomposition, powder $\mathrm{XRD}$, and batch reactor for the conversion of synthesis gas.

\subsection{Catalytic Testing of Calcined $\mathrm{Co}_{2}(\mathrm{dba})_{2} /$ silica samples}

\subsubsection{Reaction Kinetics from Batch Reactor Data.}

Monolayer and multilayer precatalysts, five grams each, described in 2.3.3 and 2.3.4 were installed in a batch reactor for catalytic testing. The Fisher-Tropsch reaction was performed at $350{ }^{\circ} \mathrm{C}$ using the reduced catalyst in a Parr batch reactor, volume $=300 \mathrm{~cm}^{3}$. The reactor was charged with the decomposed/reduced $\mathrm{Co} /$ silica catalyst. The reactor was closed and purged with nitrogen gas at atmospheric pressure and room temperature. Afterwards, the reactor was charged with $50 \% \mathrm{H}_{2} / 50 \% \mathrm{Ar}$ at $300{ }^{\circ} \mathrm{C}$ for $2 \mathrm{~h}$. The reactor was cooled to room temperature and purged with a synthesis gas mixture $\left(50 \mathrm{~mol} \% \mathrm{CO}\right.$ and $\left.50 \mathrm{~mol} \% \mathrm{H}_{2}\right)$. The temperature was increased rapidly to $350{ }^{\circ} \mathrm{C}$ and the pressure change was recorded versus time.

These data of fractional pressure $(\mathrm{P}$ at time $\mathrm{t} / \mathrm{P}$ at time $=0)$ were used to calculate fractional conversion of hydrogen, the limiting reagent: $\mathrm{f}$, using the stoichiometry for the Fischer-Tropsch reaction, see Supplemental Information.

$$
\mathrm{f}=3\left(1-\mathrm{P} / \mathrm{P}_{\mathrm{o}}\right) \quad \mathrm{Eq}(1)
$$

These data of fractional hydrogen conversion were correlated with the product of reaction time, $\mathrm{h}$, and the moles of Co in the catalyst sample, mol Co, assuming the reaction to be controlled by first order kinetics. Each of these data sets showed a linear relationship with the duration of reaction and the slopes of these curves were used to estimate the rate constants.

\subsubsection{Characterization of the Gas and Liquid Samples.}

The more active multilayer Co/silica catalyst was chosen to generate gas and liquid samples for analysis. Eight grams of this catalyst was installed in the Parr reactor at an initial pressure of 1000 psig of synthesis gas $\left(50 \mathrm{~mol} \% \mathrm{H}_{2}\right.$ and $50 \mathrm{~mol} \% \mathrm{CO}$ ) and a reaction temperature of 350 ${ }^{\circ} \mathrm{C}$. The reaction time was $96 \mathrm{~h}$ during which the total pressure dropped to $500 \mathrm{psig}$. The reactor 
was refilled with synthesis gas to a total pressure of 1000 psig and the reaction continued until the total pressure fell to a value of 500 psig. The reactor was once again refilled with synthesis gas to a total pressure of 1000 psig. The reaction was stopped and a gas sample was withdrawn for analysis by GC equipped with FID and TCD detectors. The remaining gas in the reactor, while hot, was slowly bled through a dicholomethane solution that was thermostatted at $0{ }^{\circ} \mathrm{C}$ so as to condense the products that are liquids at room conditions.

Standard gas samples, $100 \mathrm{ppm}$, diluted in inert gas were used to calibrate the GC for the major gases found in the gas sample. Five standards were used to calibrate each of the liquid samples. One micro-Liter of each standard (hexane, heptane, methyl cyclohexane, toluene, and cyclohexane) was dissolved in $1 \mathrm{~mL}$ of dichloromethane and these five standards were introduced separately into the GC to find the GC response factors for each standard. The average peak area for these standards was $1.22 \times 10^{7}$ with a standard deviation of $0.075 \times 10^{7}$.

\section{Results and Discussion}

\subsection{Characterization of Silica-Supported $\mathrm{Co}_{2}(\mathrm{dba})_{2}$ Complexes}

\subsubsection{UV-Vis spectroscopy of silica-supported $\mathrm{Co}_{2}(\mathrm{dba})_{2}$ precatalysts}

As described previously [61], UV-Vis spectroscopy is a valuable analytical tool to investigate the metal complex deposition from the solution. The UV-Vis spectrum of the $\mathrm{Co}_{2}(\mathrm{dba})_{2}$ metal solution is shown in graph (a) in Figure 2. When the metal complex was stirred with silica, the absorption of the orange-colored, solution decreased after $24 \mathrm{~h}$ as expected (shown in Figure 2(b)). Both absorption spectra have nearly the same shape before and after decorating the silica surface. This is a positive indication that unwanted reactions, such as decomposition of the metal complex, do not occur during the deposition process. The homologuous copper complex, $\mathrm{Cu}_{2}(\mathrm{dba})_{2}$, showed almost zero absorbance after $24 \mathrm{~h}$ when supported on silica [61] confirming that all of the $\mathrm{Cu}_{2}(\mathrm{dba})_{2}$ had been removed from the solution. On the other hand, the orangecolored, Co-metal complex persisted even after contact with the support for $24 \mathrm{~h}$. This result is not surprising when considering the axial coordination of water molecules to the cobalt atoms in the complex sterically hindered close interactions between the metal complex and the silica surface. When the surface absorption process takes place, dissociation of this axial ligand occurs in the solution. This process may occur through an equilibrium and can be illustrated as follows

$$
\mathrm{Co}_{2}(\mathrm{dba})_{2} \cdot 4 \mathrm{H}_{2} \mathrm{O}+\mathrm{Cab}-\mathrm{O}-\mathrm{Sil} \Leftrightarrow \mathrm{Co}_{2}(\mathrm{dba})_{2} \cdot 2 \mathrm{H}_{2} \mathrm{O} / \text { silica }+2 \mathrm{H}_{2} \mathrm{O} \quad \mathrm{Eq}(2)
$$

Equilibrium favors the forward direction with increasing concentrations of the metal solution according to Le Chatelier's principle. Therefore, the concentration of the metal complexes in solution was raised so as to increase the amount of metal complex affixed to the surface. The maximum amount of complex loading was obtained with $100 \mathrm{mg}$ complex when the mass of Cab-O-Sil is $0.5 \mathrm{~g}$. 


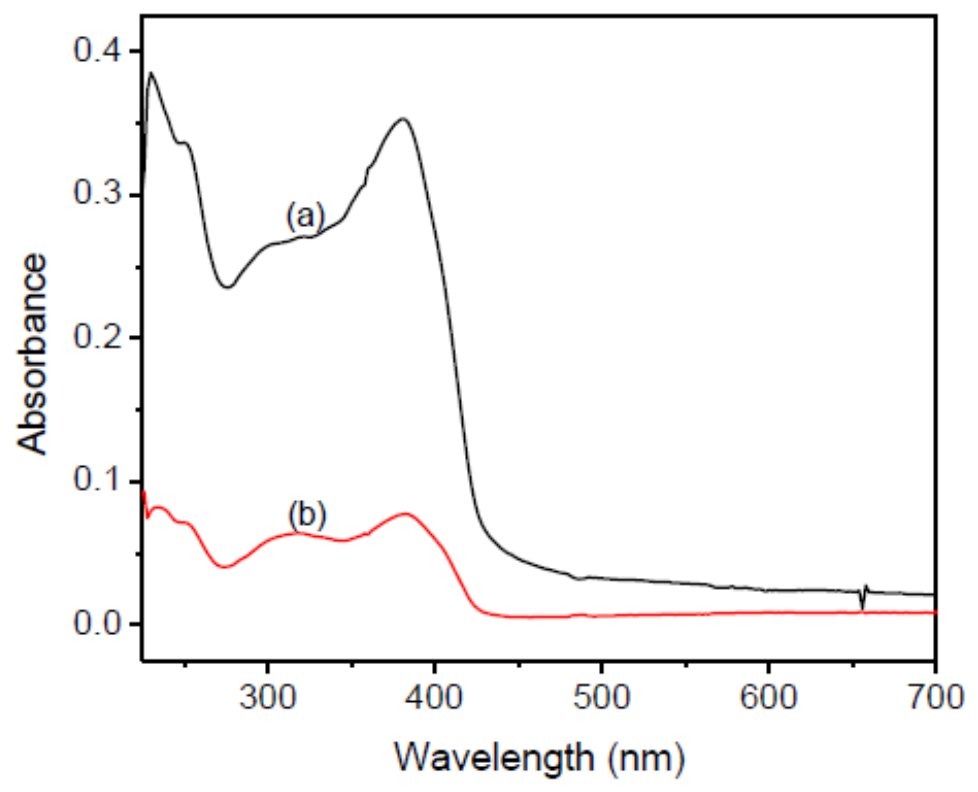

Figure 2. UV-Vis spectra of a) $1.55 \times 10^{-5} \mathrm{M} \mathrm{Co}_{2}(\mathrm{dba})_{2}$ in $\mathrm{CH}_{2} \mathrm{Cl}_{2}$ b) after stirring the same solution with $0.5 \mathrm{~g}$ Cab-O-Sil for $24 \mathrm{~h}$.

The UV-Vis absorbance change was used to calculate the amount of metal complex that was adsorbed by the Cab-O-Sil after $24 \mathrm{~h}$. The maximum absorbance peak at $380 \mathrm{~nm}$ was selected for all of the calculations as a measure of the Co metal complex solution composition and the calculated values are reported in Table S-1. Details of these calculations are shown in the ESI. These estimates of the Co and C elemental composition in the precatalysts will be compared to the experimentally determined Co and C elemental composition, Figure S-2.

\subsubsection{Elemental analysis of silica-supported $\mathrm{Co}_{2}(\mathrm{dba})_{2}$ precatalysts}

Elemental analyses were performed for all supported samples of $\mathrm{Co}_{2}(\mathrm{dba})_{2} /$ silica to determine the cobalt and carbon content. The analytical results are tabulated in Table S-3. Cobalt wt $\%$ values obtained from elemental analyses closely agree with the values calculated using data 
extracted from the UV-Vis spectra (Tables S-2 and S-3). These data of Co and C elemental analyses were plotted (Figure S-2) as mole amounts appearing in the samples prepared earlier. Both data sets show increasing amounts of $\mathrm{C}$ with increasing amounts of $\mathrm{Co}$ in the samples. The slope of these lines shows the carbon incorporation in the metal complex films. For example, the slope of the line developed from UV-Vis is 18 moles $\mathrm{C} /$ mole Co; whereas, the slope of the data developed from elemental analysis is 17.5 moles $\mathrm{C} /$ mole Co. The predicted carbon incorporation is 34 C's per 2 Co's in the metal complex; or 17 moles C/mole Co. All of the data fall in the error bars, thus the two lines are not significantly different. One could use these data to suggest that the ligands are intact and therefore the metal complexes have not decomposed upon decorating the surface. Additional data are needed to confirm this suggestion.

\subsubsection{DRIFTS of silica-supported $\mathrm{Co}_{2}(\mathrm{dba})_{2}$ precatalysts}

Figures 3 and S-3 displays the DRIFTS spectra of silica-supported, $\mathrm{Co}_{2}(\mathrm{dba})_{2}$ with different cobalt loadings and unsupported $\mathrm{Co}_{2}(\mathrm{dba})_{2}$. The $-\mathrm{OH}$ vibrations from silica and water appeared from $3500 \mathrm{~cm}^{-1}$ to $3000 \mathrm{~cm}^{-1}$ in all supported samples (see Figures 3 and S-3) and a small water peak appeared in the pure $\mathrm{Co}_{2}(\mathrm{dba})_{2}$, Figure 3, consistent with the waters of coordination. The similarity of these spectra of supported and unsupported $\mathrm{Co}_{2}(\mathrm{dba})_{2}$ in Figures 3 shows that the silica-supported metal complexes have not decomposed and are intact. In the DRIFTS spectra, however, subtle differences between the unsupported and supported $\mathrm{Co}_{2}(\mathrm{dba})_{2}$ samples were observed in the region from 800 to $1600 \mathrm{~cm}^{-1}$. In all supported $\mathrm{Co}_{2}(\mathrm{dba})_{2} /$ silica samples, a broad intense band was apparent in the region of $1000-1200 \mathrm{~cm}^{-1}$. This peak can be assigned to the $\mathrm{Si}-\mathrm{O}$ vibration $[61,62,68]$. Broad peaks were apparent from 1250 to $1600 \mathrm{~cm}^{-1}$ in the samples containing metal loadings $\leq 2.09 \mathrm{wt} \%$ cobalt. In the $2.09 \mathrm{wt} \%$ cobalt sample, a small sharp peak appears at $1600 \mathrm{~cm}^{-1}$. The intensity of this IR band increases as the metal loading increases. The same peak was apparent in the pure metal complex. In addition, several other peaks at 1560, 1390,953 , and at $801 \mathrm{~cm}^{-1}$ started to appear in samples having cobalt loadings above $2.71 \mathrm{wt} \%$. In this study, we use the vibration near $1600 \mathrm{~cm}^{-1}$ to identify those samples where extramonolayer metal complexes are present. This peak at $1600 \mathrm{~cm}^{-1}$ tentatively identified as the overtone $(2 \times C-H$, out of plane, ring $\mathrm{C})$ to the vibration at $800 \mathrm{~cm}^{-1}$, see arrow on Figure S-3. The basis for this assignment is the finding by Kenvin, et al., who observed the peak at $1552 \mathrm{~cm}^{-1}$ to appear in the spectrum as the loading of $\mathrm{Cu}(\mathrm{acac})_{2}$ surpassed a monolayer loading, vide infra [68].

In other studies, we showed how the vibrational spectrum changed for a supported mononuclear copper complex, $\mathrm{Cu}(\mathrm{acac})_{2}$ [68], and for a supported dinuclear copper complex, $\mathrm{Cu}_{2}(\mathrm{dba})_{2}$ [61], as the loading of metal complex exceeded the loading corresponding to a monolayer loading. The IR spectrum of $\mathrm{Cu}(\mathrm{acac})_{2}$ was absent a peak near $1552 \mathrm{~cm}^{-1}$ for samples having less than a monolayer loading; whereas, this peak was present in supported samples having > monolayer loadings and for unsupporated metal complexes. The IR spectrum of $\mathrm{Cu}_{2}(\mathrm{dba})_{2}$, did show a peak at $1488 \mathrm{~cm}^{-1}$ for samples having > monolayer loadings and for the sample of the unsupported $\mathrm{Cu}_{2}(\mathrm{dba})_{2}$ and this peak at $1488 \mathrm{~cm}^{-1}$ was absent in the samples having less than a monolayer loading of the complexes. The rationale for using this peak to locate monolayer completion was discussed in reference [61]. Accordingly, we will use the peak appearance at $1600 \mathrm{~cm}^{-1}$ to announce monolayer completion in the supported $\mathrm{Co}_{2}(\mathrm{dba})_{2}$ system. Therefore, it can be concluded that the monolayer coverage is completed between $1.67 \mathrm{wt} \%$ and $2.09 \mathrm{wt} \%$ 
cobalt loadings. The observation agrees well with the theoretically predicted monolayer coverage of $2.06 \mathrm{wt} \%$ cobalt loading, see Supplementary Information.

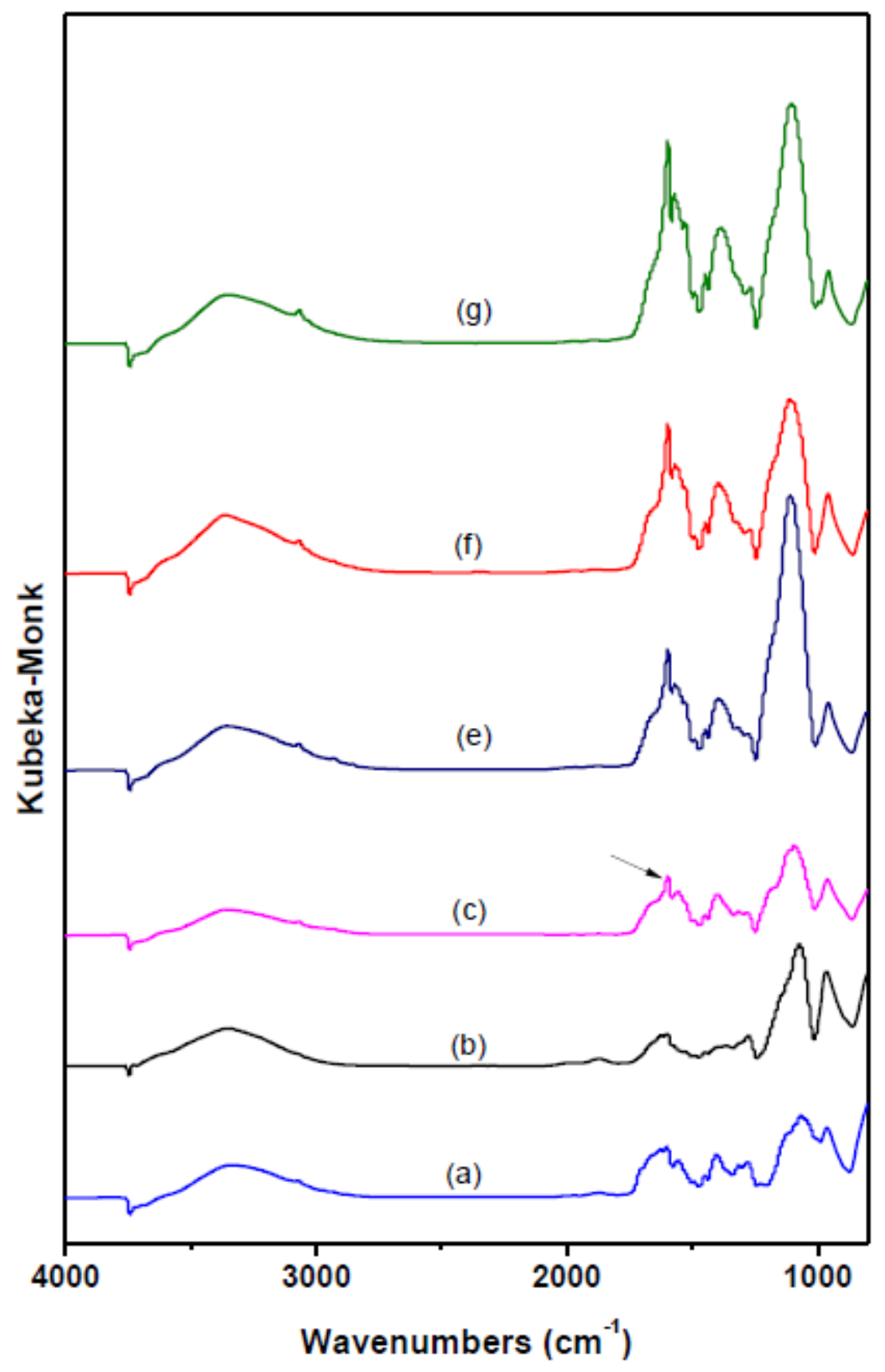

Figure 3 DRIFTS spectra of silica supported $\mathrm{Co}_{2}(\mathrm{dba})_{2}$ a) $1.19 \mathrm{wt} \% \mathrm{Co}$ b) $1.67 \mathrm{wt} \%$ Co c) 2.09 wt $\%$ Co d) $2.71 \mathrm{wt} \%$ Co e) $3.02 \mathrm{wt} \%$ Co and f) $3.34 \mathrm{wt} \%$ Co. Arrow on figure points to appearance of peak near $1600 \mathrm{~cm}^{-1}$.

The $\mathrm{Co}_{2}(\mathrm{dba})_{2} \cdot 4 \mathrm{H}_{2} \mathrm{O}$ metal complex is amorphous and does not show XRD diffraction patterns. As a result, monolayer and multilayer film formations could not be confirmed by XRD as was 
possible in earlier studies [62]. However, DRIFTS data produced satisfactory results to determine monolayer and multilayer film formation on the silica surface.

The deposition of $\mathrm{Co}_{2}(\mathrm{dba})_{2}$ metal complex onto silica surfaces takes place in $\mathrm{CH}_{2} \mathrm{Cl}_{2}$ solutions. Cobalt weight percentages on the surface could be increased with increasing concentrations of the metal solution. However, the deposition of the second layer did not occur spontaneously in $\mathrm{CH}_{2} \mathrm{Cl}_{2}$ solutions. Therefore, the second layer was forced to deposit by slowly evaporating the solvent.

Cobalt is hexacoordinate where the axial positions are occupied by water molecules. These axial ligands may not allow the dba ligands to interact with an adsorbed monolayer film in solutions to undergo the second layer deposition process.

During the $\mathrm{Co}_{2}(\mathrm{dba})_{2} /$ silica preparation process, the ligands of the $\mathrm{Co}_{2}(\mathrm{dba})_{2}$ complex remain intact. As a result, the $\mathrm{Co}_{2}(\mathrm{dba})_{2}$ complex does not lose any of its coordinated dba ligands. This was confirmed by UV-Vis (Figure 2), DRIFTS, (Figure 3) and elemental analysis, (Figure S-3). The silica surface is completely covered with $\mathrm{Co}_{2}(\mathrm{dba})_{2}$ complex above a Co loading of $2.09 \mathrm{wt} \%$.

A more precise estimation of the monolayer loading can be determined from a consideration of the DRIFTS data for the integrated area's under the $1600 \mathrm{~cm}^{-1}$ peak, see ESI, Figure S-2. All metal complexes in direct contact with silica surface, i. e., the monolayer film, do not show a peak at $1600 \mathrm{~cm}^{-1}$; whereas, metal complexes not in contact with the surface, $i$. $e$., extramonolayer metal complexes, show a vibration at this frequency. The size of this peak grows with the number of metal complexes in excess of a monolayer loading. We estimate the monolayer loading of Co to be $2.03 \mathrm{wt} \% \mathrm{Co}$; which is slightly lower than the predicted Co loading of $2.06 \mathrm{wt} \%$. Therefore, silica-supported $\mathrm{Co}_{2}(\mathrm{dba})_{2}$ monolayer films have the high dispersions of metal atoms on the surface before calcination. It is expected that after calcination, these silica supported $\mathrm{Co}_{2}(\mathrm{dba})_{2}$ complexes will be suitable model catalysts for FT synthesis.

One problem associated with the current FT catalyst is the high heat release that precludes the use of tubular flow reactors in holding the catalysts. As a result of this heat problem, a more complicated reactor design is used to accommodate the increased heat flow: the ebulating bed reactor. Given the lower loading achieved here with the very high dispersion of the Co atoms, it is expected that temperature control will be enhanced with the silica support acting as a large heat sink, thus precluding the need for the ebulating bed reactor. The other problem associated with the current FT catalyst is the broad distribution of products which requires subsequent processing to produce the desired distillate product(s). In the current work, we attempt to control the Co metal ensemble size to address this problem.

\subsection{Characterization of Decomposed, Silica-Supported $\mathrm{Co}_{2}(\mathrm{dba})_{2}$ Complexes}

\subsubsection{Kinetic data for FT reaction over decomposed $\mathrm{Co}_{2}(\mathrm{dba})_{2} /$ silica}

Two precatalysts, just over a monolayer $(2.71 \mathrm{wt} \% \mathrm{Co}$, or expressed as $2.62 \mathrm{wt} \% \mathrm{CoO}$ ) and multilayer (5.02 wt\% CoO), were calcined and reduced, vide supra, prior to the reaction. Data, Figure 4, of fractional pressure $(\mathrm{P}$ at time $\mathrm{t} / \mathrm{P}$ at time $=0)$ were used to calculate the fractional 
conversion of hydrogen, the limiting reagent when the synthesis gas is equimolar in reactants, using the stoichiometry for the Fischer-Tropsch reaction, eq. (3).

$$
(2 \mathrm{n}+1) \mathrm{H}_{2}+\mathrm{n} \mathrm{CO} \rightarrow \mathrm{C}_{\mathrm{n}} \mathrm{H}_{(2 \mathrm{n}+2)}+\mathrm{n} \mathrm{H}_{2} \mathrm{O}
$$

The composition of the syngas used here, equimolar, anticipates the commercial application where a reformer is not used and the gasifier products are cleaned before use in the FT reactor. This arrangement may be used in small volume plants where the feed could be biorenewable and thus would be small throughput facilities. The economic rationale for operating such a small plant is to capture the potential of the "carbon accountability" market.

The stoichiometry of this reaction, eq (2), shows that the total pressure of the reaction mixture decreases with increasing conversion of the reactants. The hydrogen conversions at the end of the two runs were 0.29 after $48 \mathrm{~h}$ for the monolayer catalyst and 0.92 after $18 \mathrm{~h}$ for the multilayer catalyst. Judging from the rate of pressure decrease with time, the multilayer catalyst is much more active than the monolayer catalyst.

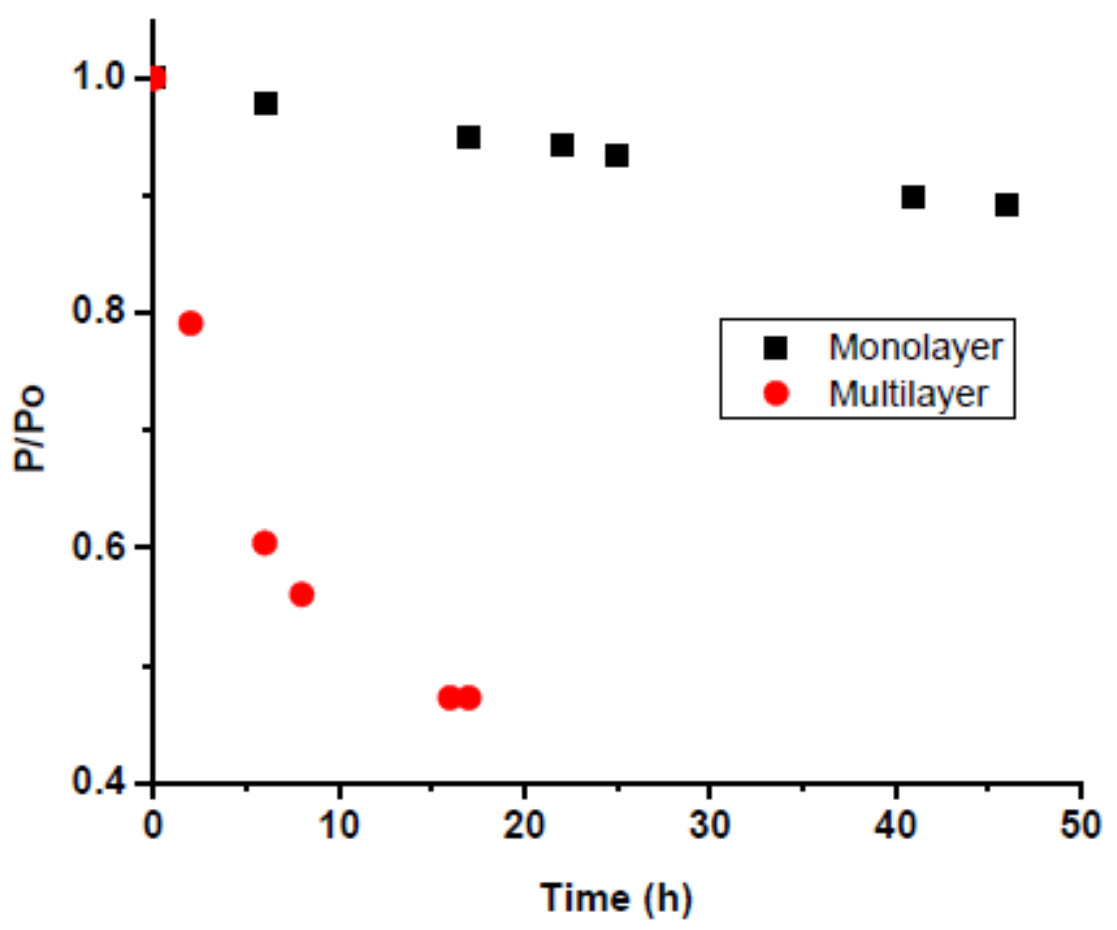

Figure 4 Batch Reactor Data of Fractional Pressure (P/Po) Change with Time of Reaction

These data of fractional hydrogen conversion were correlated with the product of reaction time, $\mathrm{h}$, and the moles of Co in the catalyst sample, assuming the reaction to be controlled by first order kinetics, Figure S-6. Each of these data sets showed a linear relationship with the duration of reaction and the slopes of these curves were used to estimate the apparent rate constants, specific to the mole of $\mathrm{Co}$ in the samples. These rate constant data show that the more active catalyst was derived from multilayer $\mathrm{Co}_{2}(\mathrm{dba})_{2} /$ silica catalyst, $\mathrm{k}_{\text {apparent }}=71.4(\mathrm{hr}-\mathrm{mol} \mathrm{Co})^{-1}$; 
whereas, the less active catalyst was derived from a monolayer of the same metal complex on

silica, $\mathrm{k}_{\text {apparent }}=2.16(\mathrm{hr}-\mathrm{mol} \mathrm{Co})^{-1}$. The apparent rate constant data show compelling proof that the catalytic particles in the monolayer catalyst are much less active than the particles in the outer layers of the multilayer catalyst.

\subsubsection{Characterization of the gas and liquid products}

Gas samples from separate experiments, Figure 4, were analyzed to characterize the light hydrocarbon and $\mathrm{CO}_{2}$ products from the samples derived from monolayer and multilayer films of the $\mathrm{Co}_{2}(\mathrm{dba})_{2}$ complexes, Figure 5. As expected the yields were lower for the gas phase products obtained over the monolayer sample when compared to the multilayer sample with $\mathrm{CO}_{2}$ and methane showing the highest yields. One striking difference between the two catalysts was observed in the ethane yields. Almost no ethane was observed in the products obtained over the monolayer catalyst as opposed to significant ethane yield was among the products observed for the multilayer catalyst. This result stands in contrast to the yields of ethylene which were similar between the two catalysts even though the activity of the monolayer sample was much smaller than the multilayer catalyst, vide supra. The carbon dioxide product may the result of the water gas/shift reaction; which apparently is favored in the sample having Co metal particles sufficiently large to be observed in the PXRD spectrum (Fig. 6).

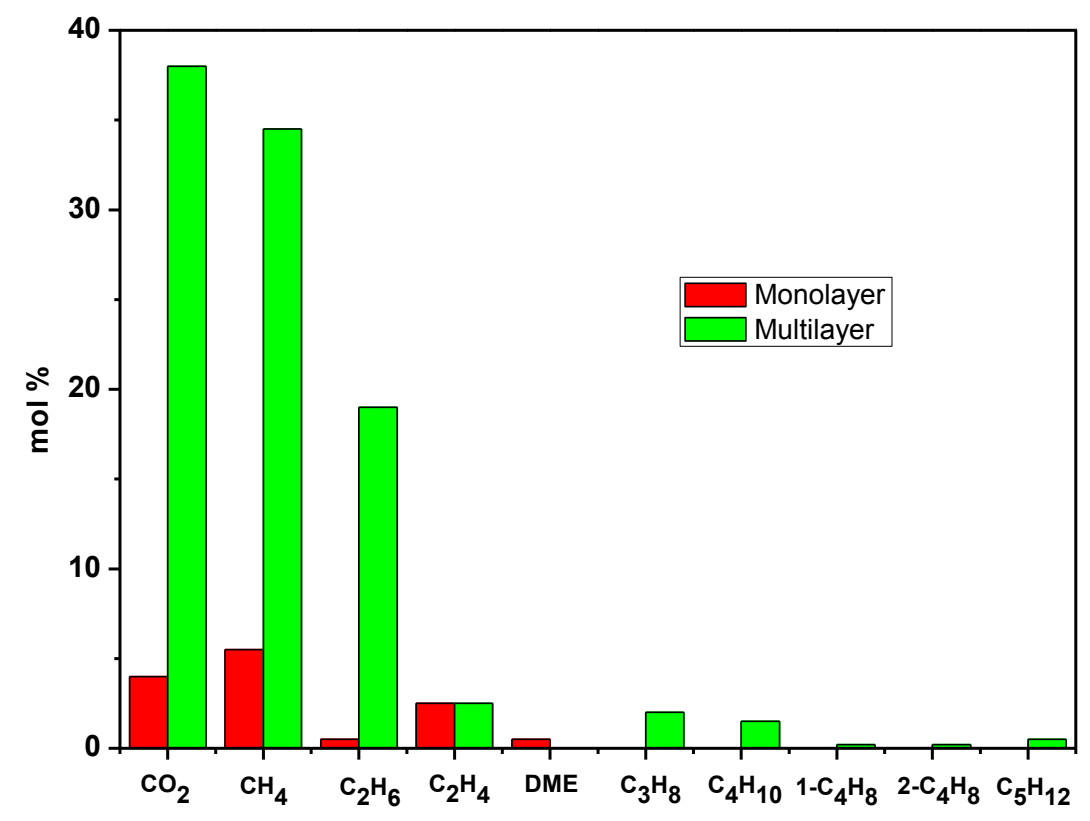

Figure 5 Analysis of gas phase products by volume $\%$ from FT reaction over catalysts derived from monolayer and multilayer films of $\mathrm{Co}_{2}(\mathrm{dba})_{2}$

One might speculate that the surface obtained by decomposition and reduction of the monolayer catalyst was less active for hydrogenation of ethylene than the surface derived from the 
multilayer. Co metal oxidation state and ensemble size play an important role in the hydrogenation activity of these catalysts, and indeed we show that the catalyst derived from the multilayer sample had large Co metal particles, vide infra, which could be observed in PXRD; whereas, the catalyst derived from the monolayer did not show any sharp PXRD lines The products observed from the monolayer catalyst also include dimethyl ether; whereas, the products from the multilayer sample do not include dimethyl ether but do show small amounts of propane, butane, 1-, and 2-butene, plus pentane. The presence of dimethyl ether confirms the lower conversion observed over the monolayer sample (29\% versus $92 \%$ ) as DME is an intermediate product in the conversion of $\mathrm{CO}$ to hydrocarbons.

No liquid sample could be obtained in these tests shown in Figure 4. We speculated that only the multilayer sample should be used to produce enough liquid sample analysis in a short time frame. Moreover, an extended time of reaction, $96 \mathrm{~h}$, with periodic refilling of reactor vessel with fresh syngas, and larger catalyst amount, $8 \mathrm{~g}$, was required to collect sufficient liquid products for analysis by GC, Figure S-7.

Table 1 Peak Assignments to the Hydrocarbon Groups Identified in Figure S-7

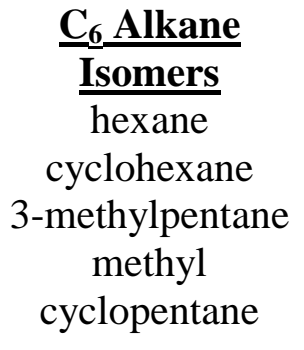

$$
\begin{gathered}
\underline{\mathbf{C}}_{7} \text { Alkane Isomers } \\
\text { methyl cyclohexane } \\
\text { 2-methylhexane } \\
\text { 2,3-dimethylpentane } \\
\text { 1,3- } \\
\text { dimethylcyclopentane } \\
\text { 1,2-dimethyl, trans } \\
\text { cyclopentane } \\
\text { methylcyclohexane } \\
\text { ethyl cyclopentane }
\end{gathered}
$$

\author{
$\underline{C}_{8}$ Alkane Isomers \\ 5-methyl-1-heptene \\ 1,2,4-trimethylcyclopentane \\ 1,2,3-trimethylcyclopentane \\ $\underline{\text { Aromatics }}$ \\ benzene \\ toluene
}

These peak assignments suggest that linear, branched, and cycloalkanes are present in the $\mathrm{C}_{6}$ and $\mathrm{C}_{7}$ hydrocarbon isomers. Among the $\mathrm{C}_{8}$ isomers is one potential alkene, however, the peak sizes are so small as to question the validity of these smaller peaks' assignments. Two aromatics were found in the sample: benzene and toluene. The solvent used to collect the liquid products, methylene chloride, does not contain benzene and toluene as impurities. Thus, we conclude that these two aromatics are reaction products. These assignments must be considered as temporary until we can analyze larger samples of the liquid hydrocarbon produced by these catalysts.

One important result is the narrow distribution of hydrocarbon products molecular weights (MW's) even though some of the products were present with the catalyst for up to $96 \mathrm{~h}$ and the reactor was filled with fresh synthesis gas for up to 3 times. This long reaction time would be sufficient for the formation of large MW hydrocarbons to form. We speculate that the particles sizes were responsible for the narrow distribution of molecular weights of the hydrocarbons. If these data can be substantiated, the results are an important step in refining the design of FT catalysts. 


\subsubsection{Powder XRD of decomposed $\mathrm{Co}_{2}(\mathrm{dba})_{2} /$ silica}

The calcined and reduced monolayer and multilayer $\mathrm{Co} /$ silica catalysts were examined by powder XRD to describe the nature of the Co particles in these samples (Figure 6). The sample derived from a monolayer of $\mathrm{Co}_{2}(\mathrm{dba})_{2}$ complexes showed only one broad peak at $2 \theta=$ 16-17 degrees (not shown, see reference 61, Ph. D. thesis); whereas, the sample derived from a multilayer of $\mathrm{Co}_{2}(\mathrm{dba})_{2}$ complexes shows two peaks. These peaks are located at 16-17 degrees and 44.5 degrees. The broad peaks at 16-21 degrees $2 \theta$ can be attributed to the amorphous Cab-O-Sil support [67] and the sharp peak at 44.5 degrees $2 \theta$ has been attributed to a metallic $\mathrm{Co}(111)$ reflection [69]. The sharp peak at 44.5 degrees suggests that the Co atoms in the multilayer sample formed large metal particles upon calcination in air and reduction in $\mathrm{H}_{2}$ and these Co particles are sufficiently large to be observed in PXRD. On the other hand, the absence of any peak at 44.5 degrees in the sample derived from a monolayer of metal complex suggests that the metal particles, if any, are too small to be observed in PXRD. Earlier work on silica-supported $\mathrm{Cu}(\mathrm{acac})_{2}$ showed that large $\mathrm{Cu}$ metal particles formed in a sample derived from a multilayer of film $\mathrm{Cu}(\mathrm{acac})_{2}$ [62]; whereas, only small $\mathrm{Cu}$ particles (i.e., XRD amorphous) were formed from a monolayer film of silica-supported $\mathrm{Cu}(\mathrm{acac})_{2}$. The reactivity to hydrocarbon probe reactions of these copper systems, reducibility, reoxidation kinetics, metal dispersion (by $\mathrm{NO}$ titration) and reactivity to $\mathrm{N}_{2} \mathrm{O}$ depended upon the initial disposition of the $\mathrm{Cu}(\mathrm{II})$ complexes on silica (monolayer vs multilayer) [62]. From a knowledge of the chemistry found in the $\mathrm{Cu}(\mathrm{acac})_{2}$ system, we speculate that the $\mathrm{Co}_{2}(\mathrm{dba})_{2}$ behaves similarly.

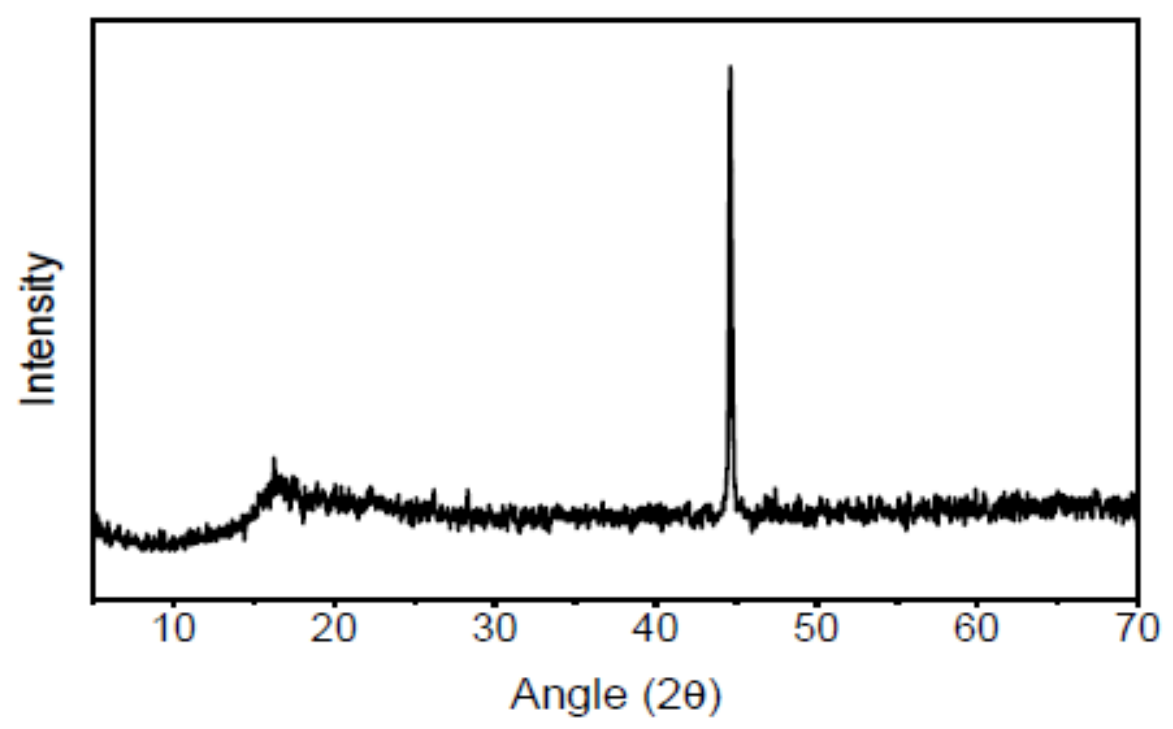

Figure 6 Powder XRD of Decomposed and Reduced Multilayer $\mathrm{Co}_{2}(\mathrm{dba})_{2} /$ silica

\subsubsection{TEM images of Co/silica catalysts before and after FT reaction}

$\mathrm{Co} /$ silica $\left[\mathrm{Co}_{2}(\mathrm{dba})_{2}\right]$ multilayer $(5.02 \mathrm{wt} \% \mathrm{CoO})$ catalyst was examined by TEM after the sample was used in a reaction to convert synthesis gas to hydrocarbons. The TEM image, Figure 7-A, showed tubular-like structures, arrows. One structure, see insert, was approximately 50-70 nm in length and the tubular nature of the structure was apparent in this image. However, the sample formed from $\left[\mathrm{Co}_{2}(\mathrm{dba})_{2}\right]$ on silica containing just above a monolayer of $\left[\mathrm{Co}_{2}(\mathrm{dba})_{2}\right](2.62 \mathrm{wt} \% \mathrm{CoO} /$ silica $)$, Figure 7-B, did not show these tube-like structures. Consider the control sample, Figure 7-C, a TEM image of the $5.02 \mathrm{wt} \% \mathrm{CoO} /$ silica sample before exposure to the synthesis gas reaction. No tubular structures 
were found in this sample which means that the tubular structures were formed during the syngas reaction. Apparently, the loading of $\mathrm{Co} /$ silica had an influence on the formation of these tubular structures during the synthesis gas reaction. The XRD data, Figure 6, showed that crystalline Co was present in the sample that formed the nanotubes during the conversion of the syngas.

We turn now to the identification of the tubular structures shown in Figure 7-A. We did not examine these samples for carbon elemental analysis; therefore, we cannot comment on whether carbon was present in the sample shown in Figure 7-A. Since these structures were formed during the syngas reaction, one might speculate that these structures may be composed of carbon growing from the cobalt surface. The possible structures are C-nanotubes, graphite, \& some combination of $\mathrm{C}$ and Co structures. Figure 7-A. Insert

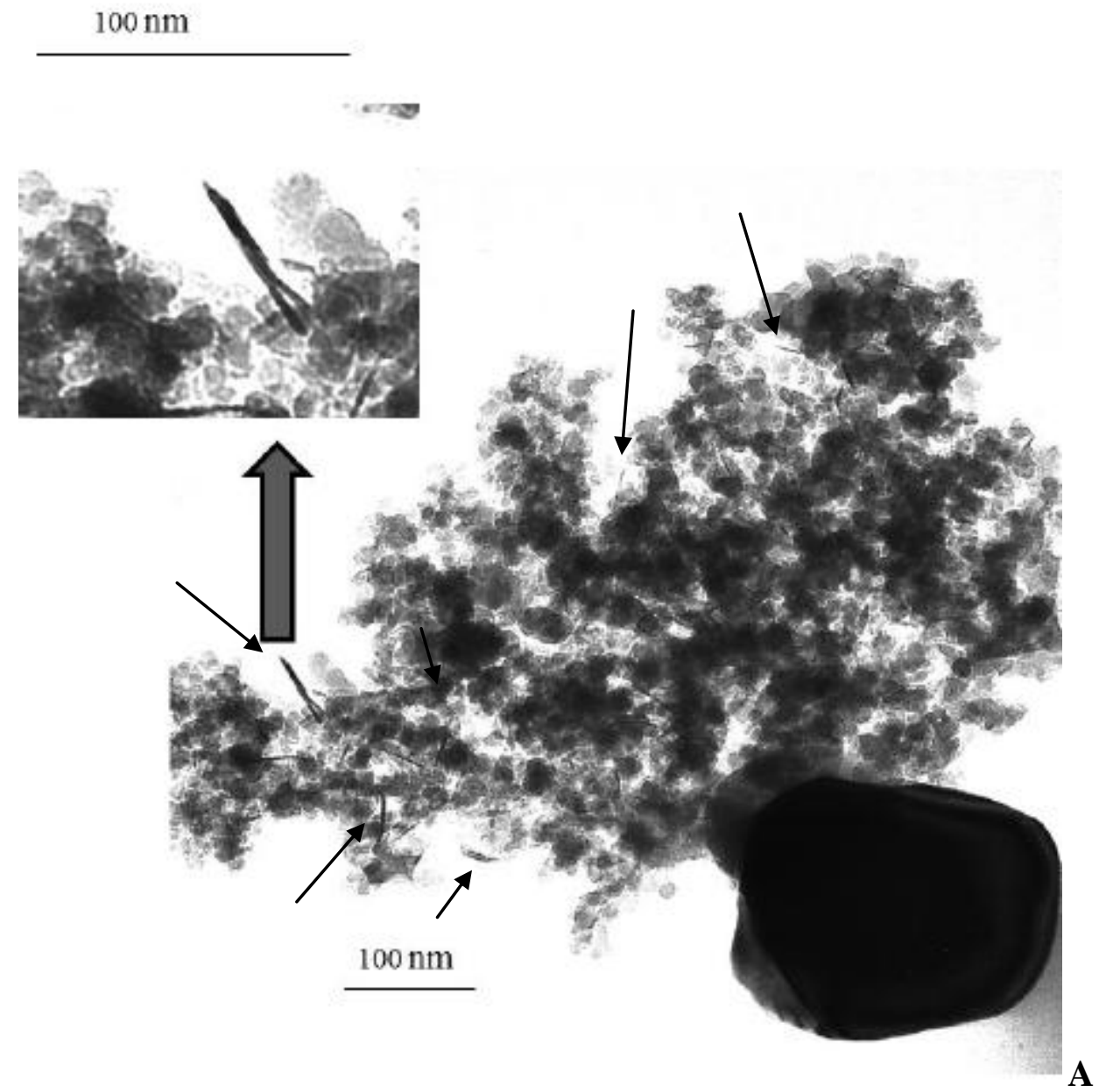



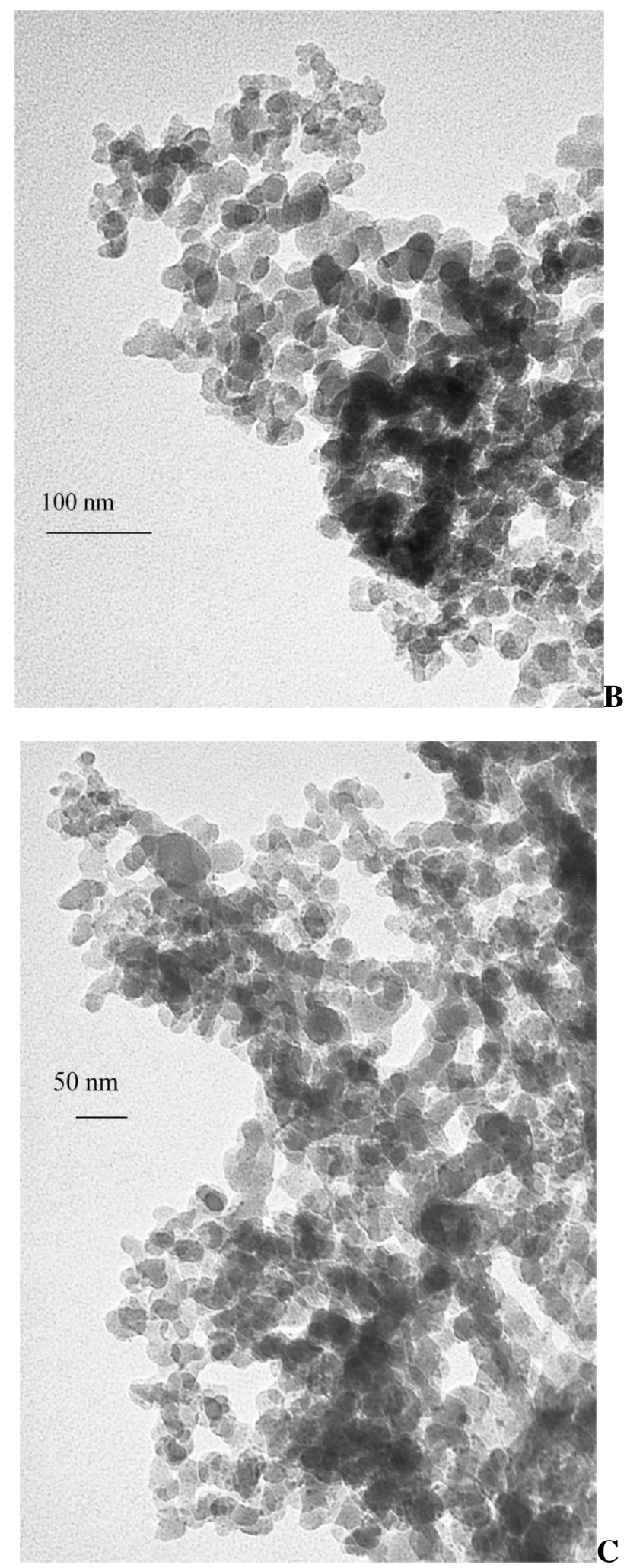

Figure 7 TEM of Co/silica Catalyst After Synthesis Gas Reaction. A) 5.02 wt\% CoO/silica, B) 2.62 wt\% CoO/silica, C) 5.02 wt\% CoO/silica before Synthesis Gas Reaction 
Carbon nanotubes were detected in large yields from the $\mathrm{CO}$ conversion at $750 \mathrm{C}$ over $\mathrm{Co} /$ silica samples formed from the decoration of the silica using $\mathrm{Co}(\mathrm{acac})_{2}$ and $\mathrm{Co}(\mathrm{acac})_{3}$. [70] The Co loadings on these samples were similar to the metal loadings we used here: $3-4 \mathrm{wt} \%$ Co. The authors [70] suggested that SWNT's were formed as follows: "the active sites for SWNT synthesis are small cobalt particles resulting from the reduction of a highly dispersed surface cobalt silicate species". These $\beta$-diketonate ligands used in this study are similar to the triketonate ligands used in our study thus we suggest that the tubular structures, Figure 7-A, could be carbon nanotubes. We believe that the $\mathrm{Co} /$ silica samples derived from multilayers of dinuclear Co triketonates possess some of the same Co sites necessary to form these nanotubes; however, the number of these sites is small and the number of nanotubes in our samples is much smaller than the number reported by the authors of reference [70].

\subsection{Discussion -- Decoration of Silica Surface by $\mathrm{Co}_{2}(\mathrm{dba})_{2}$}

Our previous work with metal diketonates showed that some of the species decorated the silica surface intact employing a hydrogen-bonding interaction to initially anchor the complex to the surface. Evidence of the H-bonding between surface silanols was furnished from an inspection of the IR spectrum where the ring, C-H out-of-plane overtone was missing in these spectra of the monolayer and sub-monolayer samples. Moreover, our recent work decorating the silica surface with a dinuclear $\mathrm{Cu}(\mathrm{II})$ complex having triketonate ligands also showed the strong binding between the complex and the surface, and also demonstrated the same response of the IR spectrum with increasing loading of complex (i. e., missing peak at $1488 \mathrm{~cm}^{-1}$ for submonolayer samples [61]). Given that the IR data in the present work also shows one or more peaks missing in the IR spectra of the sub-monolayer samples, we speculate that the same explanation is valid in the present system for attracting and anchoring the Co dinuclear metal complexes to the silica surface.
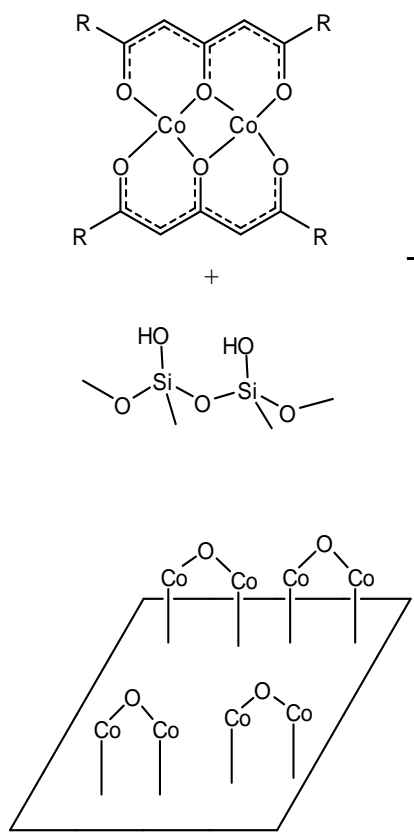

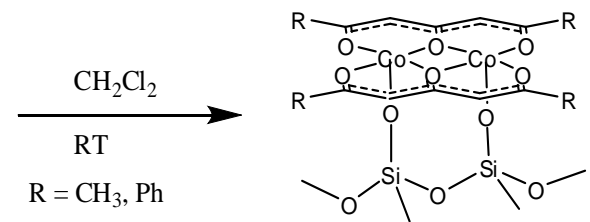

Calcination $450^{\circ} \mathrm{C}$
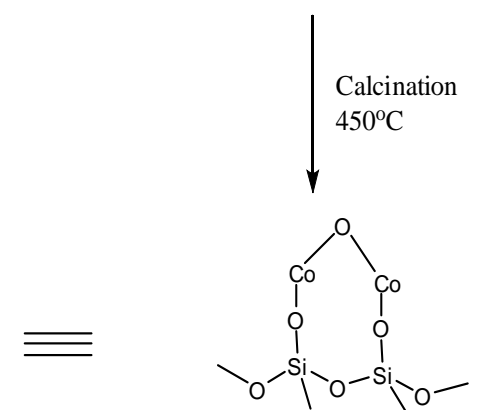

\section{Scheme I Mechanism for $\mathrm{Co}_{2}(\mathrm{dba})_{2}$ Decorating Silica Surface to Yield $\mathrm{Co}(\mathrm{II}) / \mathrm{SiO}_{2}$}


Accordingly, we propose Scheme I as one mechanism by which the $\mathrm{Co}_{2}(\mathrm{dba})_{2}$ complex decorates the silica surface. Two surface silanols hydrogens interact with one (dba) ligand to liberate the corresponding triketone. The resulting two surface siloxides enter the coordination spheres of the two $\mathrm{Co}$ (II) cations to anchor to the silica surface the residue, $\mathrm{Co}_{2}(\mathrm{dba})$, of the original complex. During the calcinations process, the remaining dba ligand decomposes to give a pair of surface bound Co's species binding to two siloxides and to a bridging oxygen anion. Here, we have assumed that the Co species are +2 oxidation state. Alternatively, the surface Co's could oxidize to the +3 state and therefore more oxygens are needed to balance the charges on the cations. Moreover, these Co species may react with $\mathrm{H}_{2} \mathrm{O}$ to form a surface where each $\mathrm{Co}(\mathrm{II})$ or $\mathrm{Co}$ (III) is bonded to a terminal $-\mathrm{OH}$ group(s). When a second layer of Co triketonate metal complexes is present, the top layer easily organizes into crystallites of cobalt oxide which is much more easily reduced into Co metal particles than the Co species in contact with surface siloxides, first layer.

The morphology of the decomposed catalysts depends upon the initial state of the supported metal complex. While we did not measure the reducibility of these samples directly using TPR, one can deduce the reducibility of the two samples from a consideration of the PXRD. The sample derived from the multilayer film of $\mathrm{Co}_{2}(\mathrm{dba})_{2}$ compleces showed a sharp PXRD peak at the position of $2 \theta$ expected for metallic Co $\left(\sim 44^{\circ}\right)$. Since the metal complex was divalent Co, initially, the observation of metallic Co in the reduced/reacted sample is clear evidence that a significant amount of Co was reduced in this sample. On the other hand, the sample derived from a monolayer of the same metal complex, showed no evidence of crystalline Co metal, even though the amount of $\mathrm{Co}$ (II) in this sample was $1 / 2$ that of the amount of $\mathrm{Co}(\mathrm{II})$ present in the multilayer sample (2.6 wt \% vs $5.0 \mathrm{wt} \%)$. Possible interpretations of these data include: 1) the Co species developed from the monolayer film were too small to be observed by PXRD and by TEM, and therefore did not sinter. A reason for these results seen in PXRD and TEM is that the Co species originating from a monolayer film were strongly attached to the silica and this attachment prevented sintering and/or reduction of the Co species to metallic Co. For this reason, we believe that monolayer dispositions of the metal complex on silica, after decomposition and reduction, led to highly dispersed metal and/or metal oxides that do not sinter and therefore do not give rise to PXRD reflections. On the other hand, decomposition and reduction of a multilayer disposition of the metal complexes led to supported metal particles showing a sharp reflection assigned to the $\mathrm{Co}(111)$ index. We speculate that some, well-dispersed $\mathrm{CoO}_{\mathrm{x}}$ could be present in the higher loading samples after decomposition but these species did not show PXRD spectra and did not appear in the TEM images.

\subsection{Discussion of FT Activity}

Two pre-catalyst samples were prepared having an initial disposition of the metal complexes as just over a monolayer $(2.09 \mathrm{wt} \% \mathrm{Co}, 2.62 \mathrm{wt} \% \mathrm{CoO})$ and a sample containing an amount of metal complexes equal to $\sim 2$ monolayers $(5.02 \mathrm{wt} \% \mathrm{CoO})$. When calcined in air and reduced in hydrogen, these activated catalysts were active for the FT reaction. The sample developed from the larger Co loading showed a much higher reactivity as characterized by first order rate constants: 71.4 vs 2.16 (moles Co-h) ${ }^{-1}$, Figure S-6. Notice that these rate constants have been normalized to the amount of Co species in the samples. 
We may understand better these activity data when we consider the PXRD and TEM data (vide supra). The multilayer sample showed the presence of Co crystals in the XRD (Figure 6) and these features were not observed in the catalyst prepared from $\mathrm{Co}_{2}(\mathrm{dba})_{2}$ monolayer film samples. It is known that Co metal is an active catalyst for the FT reaction and therefore, the lower reactivity of the sample derived from the monolayer film of $\mathrm{Co}_{2}(\mathrm{dba})_{2}$ vis a vis the multilayer sample could mean that the monolayer film sample contained very little Co metal.

The model catalysts prepared here are much less reactive and less selective to liquid hydrocarbons than those made by customary methods reported in the literature [71]. However, the model catalysts are useful in learning how the catalyst precursors (Co(II) species) interact with the support surface during the initial formation of the catalyst. In addition, these model catalysts afford a partial knowledge of the relationships between the $\mathrm{Co} /$ silica surface morphology and the physical/catalytic properties

The narrow distribution of liquid hydrocarbons obtained over the higher loaded Co/silica sample is not easy to explain. Such narrow distributions of hydrocarbons have been observed for the syngas to liquids reaction obtained from a Mo/ZSM-5 where reactive intermediates were developed inside the zeolite pore network and the small size of this network ( 0.5-0.6 nm) regulated the size of hydrocarbons ultimately formed in these catalysts. [72] One could speculate that the tubular structures observed in the Co/silica sample may play a similar role to exercise shape selectivity to the intermediates. Others have reported the formation of multiwalled, carbon nanotubes containing Co species from the decomposition of a lysine cobalt(II) complex. [73] Crystalline nanotubes showed dimensions of 11-18 nm as measured by XRD. We observed one large, nanotube, Figure 7-A (see Insert) measuring 70 nanometers long and showed one end with a diameter of $10 \mathrm{~nm}$ whereas, the nanotube opening at the other end was $<5 \mathrm{~nm}$. Other tube-like features in the figure show smaller dimensions, perhaps $1 \mathrm{~nm}$ in diameter by $10 \mathrm{~nm}$ long. If these smaller features were nanotubes containing Co species, these structures could exercise shape-selective functions to create a liquid mixture of hydrocarbons with a narrow MW distribution, provided that the inside diameters of these tubes were $0.5-0.6 \mathrm{~nm}$.

\subsection{Conclusions}

$\mathrm{Co}_{2}(\mathrm{dba})_{2}$ complexes were successfully supported on silica surfaces and characterized using the same techniques used in previous investigations [61,62]. This technique allows us to design cobalt pre-catalysts spaced uniformly on the silica surface and creating mono and multilayer forms. The $\mathrm{Co}_{2}(\mathrm{dba})_{2}$ complex forms multilayer films at loading $\geq 2.09 \mathrm{wt} \% \mathrm{Co}$. These samples derived from decomposing the multilayer films of $\mathrm{Co}_{2}(\mathrm{dba})_{2}$ were active for the FT reaction and produced a hydrocarbon liquid product, rich in iso- and cycloalkanes, showing a narrow distribution of MW's between 78 and 112. Tubular structures were created in these samples derived from multiple layers of $\mathrm{Co}_{2}(\mathrm{dba})_{2}$ when the catalyst was used to convert syngas to hydrocarbons. We speculate that these tubular structures could be responsible for the narrow distribution of MW's observed in the liquid products. 


\subsection{Acknowledgements}

This manuscript is based upon work performed through the Sustainable Energy Research Center at Mississippi State University and was supported by the Department of Energy under Award Number DE-FG3606GO86025.

Special acknowledgement is made to Dr. W. P. Henry, an author and principal investigator, for his lifetime dedication to inorganic chemistry. Dr. Henry suddenly died of lung cancer (February, 2014).

Disclaimer: This report was prepared as an account of work sponsored by an agency of the United States Government. Neither the United States Government nor any agency thereof, nor any of their employees, makes any warranty, express or implied, or assumes any legal liability or responsibility for the accuracy, completeness, or usefulness of any information, apparatus, product, or process disclosed, or represents that its use would not infringe privately owned rights. Reference herein to any specific commercial product, process, or service by trade name, trademark, manufacturer, or otherwise does not necessarily constitute or imply its endorsement, recommendation, or favoring by the United States Government or any agency thereof. The views

and opinions of authors expressed herein do not necessarily state or reflect those of the United States Government or any agency thereof.

\subsection{References}

1. Mondal R, Bhunia MK, Dhara K (2008) Cryst Eng Comm 10:1167-1174

2. Long JR, Yaghi OM (2009) Chem Soc Rev 38:1213-1214

3. O'Keeffe M (2009) Chem Soc Rev 38:1215-1217

4. Spokoyny AM, Kim D, Sumrein A, Mirkin CA (2009) Chem Soc Rev 38:1218-1227

5. Kuppler RJ, Timmons DJ, Fang QR, Li JR et al (2009) Coord Chem Rev 253:3042-3066

6. Czaja AU, Trukhan N, Mu“ller U (2009) Chem Soc Rev 38:1284-1293

7. Murray LJ, Dinca M, Long JR (2009) Chem Soc Rev 38:1294-1314

8. Allendorf MD, Bauer CA, Bhakta RK, Houk RJT (2009) Chem Soc Rev 38:1330-1352

9. Kurmoo M (2009) Chem Soc Rev 38:1353-1379

10. Dry ME in: Anderson JR, Boudart M (Eds.), Catalysis Sciences and Technology, Vol. 1, Springer, Berlin, 1981, p. 159.

11. Ponec V, Bond GC (1995) Stud Surf Sci Catal 95; 704.

12. Iglesia E (1997) Appl Catal A 161:59-78

13. Krishnamoorthy S, Tu M, Ojeda MP, Pinna D, Iglesia E (2002) J Catal 211:422.

14. Ruckenstein E, Wang HY (2000) Appl. Catal. A 204:257.

15. Kainulainen TA, Niemelä MK, Krause AOI (1998) Catal. Lett. 53:97.

16. Taylor WF, Staffin HK (1967) J. Phys. Chem. 71:3314.

17. Völter J, Hermann M, Heise K (1968) J. Catal. 12:307.

18. Ho SW, Cruz JM, Houalla M, Hercules DM (1992) J. Catal. 135:173.

19. Ando C, Kurokawa H, Miura H (1999) Appl. Catal. A 185:L181.

20. Motchelaho AMM (2011) Ph.D. Dissertation, University of the Witwatersrand.

21. Zhang Y, Wei D, Hammache S, Goodwin JG (1999) J. Catal. 188:281-290.

22. Khodakov AY, Griboval CA, R. Bechara VZ (2002) J. Catal. 206:230-241. 
23. Martinez A, Lopez C, Marquez F, Diaz I (2003) J. Catal. 220:486-499.

24. Flory PJ (1936) J. Am. Chem. Soc. 58: 1877.

25. Jager B (1998) Stud. Surf. Sci. Catal. 119: 25-34.

26. Iglesia E, Reyes SC, Madon RJ, Soled SL, Eley DDHP, Paul BW. (1993) Adv. Catal. 39:221-302.

27. Iglesia E, Soled SL, Fiato RA (1992) J. Catal.137:212-224.

28. Soled SL, Iglesia E, Fiato RA, Baumgartner JE, Vroman H, Miseo S (2003) Top. Catal. 26:101-109.

29. Khodakov AY, Chu W, Fongarland P (2007) Chem. Rev. 107:1692-1744.

30. Wang ZJ, Yan Z, Liu CJ, Goodman DW (2011) Chem. Cat. Chem. 3:551-559.

31. Oosterbeek H (2007) Phys. Chem. Chem. Phys. 9:3570-3576.

32. Geerlings JJC, Zonnevylle MC, Groot CPM (1990) Catal. Lett. 5:309-314

33. Geerlings JJC, Zonnevylle MC, Groot CPM (1991) Surf. Sci. 241:302-314.

34. Chin RL, Hercules DM, (1982) J. Phys. Chem. 86:360.

35. Reuel RC, Bartholomew CH (1984) J. Catal. 85:78.

36. Roe GM, Ridd MJ, Cavell KJ, Larkins FP (1988) Stud. Surf. Sci. Catal. 36:509.

37. Chan IY, Castner DG, Watson PR (1990) J. Phys. Chem. 94:819.

38. Puskas I, Fleisch TH, Hall JB, Meyers BL, Rochinski RT (1992) J. Catal.134:615.

39. Van Steen E, Sewell GS, Makhothe RA, Micklethwaite C, Manstein H, De Lange M,

O`Connor CT (1996) J. Catal. 162:220.

40. Noronha FB, Schmal M, Nicot C, Moraweck B, Frety R (1997) J. Catal.168:42.

41. Kraum M, Baerns M (1999) Appl. Catal. A 186:189.

42. Riva R, Miessner H, Vitali R, Del Piero G (2000) Appl. Catal. A 196:111.

43. Backman LB, Rautiainen A, Lindblad M, Krause AOI (2000) Appl. Catal. A 191:55.

44. Voß M, Borgmann D, Wedler G (2002) J. Catal. 212:10.

45. Rosynek MP, Polansky CA (1991) Appl. Catal. 73:97.

46. Okamoto Y, Nagata K, Adachi T, Imanaka T, Inamura K, Takyu T (1991) J. Phys. Chem. 95:310.

47. Matsuzaki T, Takeuchi K, Hanaoka H, Arakawa H, Sugi Y (1996) Catal.Today 28:251.

48. Sun S, Tsubaki N, Fujimoto K (2000) Appl. Catal. A 202:121.

49. Riva R, Miessner H, Vitali R, Del Piero G (2000) Appl. Catal. A 196:111.

50. Srinivasan R, De Angelis RJ, Reucroft PJ, Dhere AG, Bentley J (1989) J. Catal. 116:144.

51. Ming H, Baker BG (1995) Appl. Catal. A 123:23.

52. Khodakow AYu, Lynch J, Bazin D, Rebours D, Zanier B, Moisson B, Chaumette P (1997) J. Catal. 168:16.

53. Barbier A, Hanif A, Dalmon JA, Martin GA (1999) Appl. Catal. A 168:333.

54. Ernst B, Libs S, Chaumette P, Kiennemann A (1998) Appl. Catal. A 186:145.

55. Coulter KE, Sault AG (1995) J. Catal. 154:56.

56. Kogelbauer A, Weber JC, Goodwin JG (1995) Catal. Lett. 34:259.

57. Ho SW, Houalla M, Hercules DM (1990) J. Phys. Chem. 946396.

58. Jabłoński JM, Okal J, Potoczna-Petru D, Ludwina Krajczyk L. (2003) J. Catal. 220:146-160.

59. Jongsomjit B, J. Panpranot J, Goodwin JG (2001) J. Catal. 204:98.

60. Juszczyk W, Łomot D, Pielaszek J, Karpiński Z (2002) Catal. Lett. 78:95.

61. Ranaweera, SA, Ph. D. thesis, Dept. of Chemistry, Mississippi State University, (2012);

Ranaweera SA, Rowe MD, Walters KB, Henry WP, White MG, Rodriguez JM (2014) Inorg. Chem. Acta 423:281-289.

62. White Mark G, Catal. Today, vol. 18, No. 1, pp. 73-109, (1993). 
63. Miles ML, Hauser CR, Harris TM (1965) J. Org. Chem. 30:1007-1011.

64. Cea-Olivers R, Rodriguez I, Rosales, MJ, Toscano RA (1987) Aust. J. Chem. 40:1127-1130.

65. Kuszaj JM, Tomlonovic B, Murtha DP, Linntvedt RL, Glick MD (1973) Inorg. Chem. 12:1297-1303..

66. http://chemister.ru/Database/properties-en.php?dbid=1\&id=573

67. Miles, M. L.; Hauser, C. R.; Harris, T. M. (1965) J. Org. Chem 30, 1007-1011.

68. Kenvin, J. C., M. G. White and M. B. Mitchell, Lang. 7, pp. 1198-1205, (1991).

69. Glaspell, G.P.; Jagodzinski, P.W.; Manivannan, A. J. Phys. Chem. B 2004, 108, 9604-9608.

70. Li, N.; Wang, X.; Derrouiche, S.; Haller, G. L.; Pfefferle, L. D. ACS Nano, 4, 2011, 1759-1767.

71. Pendyala, V R R, G Jacobs, C Bertaux, S Khalid, B H Davis, Journal of Catalysis 337 (2016) 80-90.

72. Liu, S, A C Gujar, P Thomas, H Toghiani; M G White, Applied Catalysis, A: General, 2009, 357, 1825.

73. Shailesh, S. K., A. K. Roy, and B. Tiwari, International Journal of Materials, Mechanics and Manufacturing, Vol. 2, No. 1, February 2014 
Figure Captions:

1. Structure of dicobalt complex used in this study; $\mathrm{Ph}=$ phenyl group

2. UV-Vis spectra of a) $1.55 \times 10^{-5} \mathrm{M} \mathrm{Co}_{2}(\mathrm{dba})_{2}$ in $\mathrm{CH}_{2} \mathrm{Cl}_{2}$ b) after stirring the same solution with $0.5 \mathrm{~g}$ Cab-O-Sil for $24 \mathrm{~h}$.

3. DRIFTS spectra of silica supported $\mathrm{Co}_{2}(\mathrm{dba})_{2}$ a) $1.19 \mathrm{wt} \% \mathrm{Co}$ b) $1.67 \mathrm{wt} \% \mathrm{Co}$ c) $2.09 \mathrm{wt} \%$ Co d) $2.71 \mathrm{wt} \%$ Co e) $3.02 \mathrm{wt} \%$ Co and f) $3.34 \mathrm{wt} \%$ Co. Arrow on figure points to appearance of peak near $1600 \mathrm{~cm}^{-1}$.

4. Batch Reactor Data of Fractional Pressure $\left(\mathrm{P} / \mathrm{P}_{\mathrm{o}}\right)$ Change with Time of Reaction

5. Analysis of gas phase products by volume $\%$ from FT reaction over catalysts derived from monolayer and multilayer films of $\mathrm{Co}_{2}(\mathrm{dba})_{2}$

6. Powder XRD of Decomposed and Reduced Multilayer $\mathrm{Co}_{2}(\mathrm{dba})_{2} /$ silica

7. TEM of Co/silica Catalyst After Synthesis Gas Reaction. A) $5.02 \mathrm{wt} \%$ $\mathrm{CoO} /$ silica, B) $2.62 \mathrm{wt} \% \mathrm{CoO} /$ silica, C) $5.02 \mathrm{wt} \% \mathrm{CoO} /$ silica before Synthesis Gas Reaction 
Table 1 Peak Assignments to the Hydrocarbon Groups Identified in Figure S-7

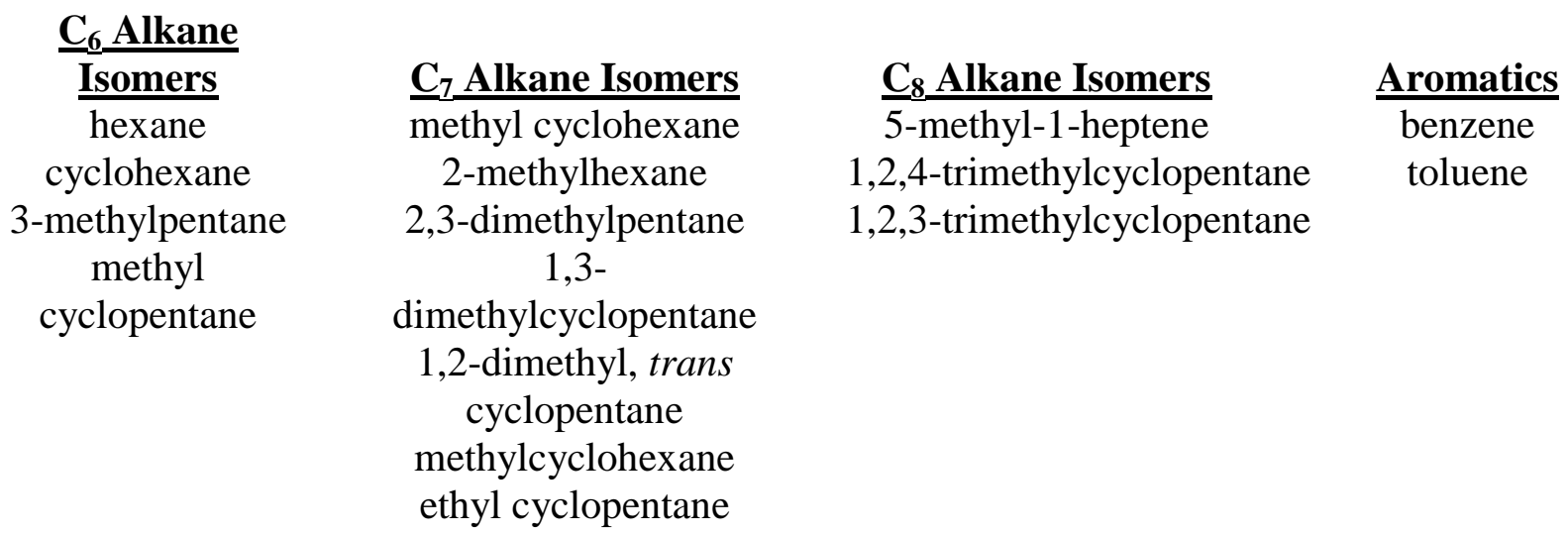


Figure Captions:

1. Structure of dicobalt complex used in this study; $\mathrm{Ph}=$ phenyl group

2. UV-Vis spectra of a) $1.55 \times 10^{-5} \mathrm{M} \mathrm{Co}_{2}(\mathrm{dba})_{2}$ in $\mathrm{CH}_{2} \mathrm{Cl}_{2}$ b) after stirring the same solution with $0.5 \mathrm{~g} \mathrm{Cab}-\mathrm{O}-\mathrm{Sil}$ for $24 \mathrm{~h}$.

3. DRIFTS spectra of silica supported $\mathrm{Co}_{2}(\mathrm{dba})_{2}$ a) $1.19 \mathrm{wt} \% \mathrm{Co}$ b) $1.67 \mathrm{wt} \% \mathrm{Co}$ c) $2.09 \mathrm{wt} \%$ Co d) $2.71 \mathrm{wt} \%$ Co e) $3.02 \mathrm{wt} \%$ Co and f) $3.34 \mathrm{wt} \%$ Co. Arrow on figure points to appearance of peak near $1600 \mathrm{~cm}^{-1}$.

4. Batch Reactor Data of Fractional Pressure $\left(\mathrm{P} / \mathrm{P}_{\mathrm{o}}\right)$ Change with Time of Reaction

5. Analysis of gas phase products by volume $\%$ from $\mathrm{F} / \mathrm{T}$ reaction over catalysts derived from monolayer and multilayer films of $\mathrm{Co}_{2}(\mathrm{dba})_{2}$

6. Powder XRD of Decomposed and Reduced Multilayer $\mathrm{Co}_{2}(\mathrm{dba})_{2} /$ silica

7. TEM of Co/silica Catalyst After Synthesis Gas Reaction. A) $5.02 \mathrm{wt} \%$ $\mathrm{CoO} /$ silica, B) $2.62 \mathrm{wt} \% \mathrm{CoO} /$ silica, C) $5.02 \mathrm{wt} \% \mathrm{CoO} /$ silica before Synthesis Gas Reaction 


\title{
Synthesis, Characterization and Catalytic Activity of a Cobalt Catalyst: Silica-Supported, bis(1,5-diphenyl-1,3,5-pentanetrionato)dicobalt(II) [ $\left.\mathrm{Co}_{2}(\mathrm{dba})_{2}\right]$
}

\author{
S. A. Ranaweera ${ }^{\mathrm{a}, \mathrm{d}}$, M. D. Rowe ${ }^{\mathrm{b}}$, K. B. Walters ${ }^{\mathrm{b}}$, W. P. Henry ${ }^{\mathrm{a} \dagger}$, M. G. White ${ }^{\mathrm{b} *}$, \\ J. M. Rodriguez ${ }^{\mathrm{c}}$
}

${ }^{a}$ Department of Chemistry, Mississippi State University, Mississippi State, MS 39762, USA

${ }^{b}$ Dave C. Swalm School of Chemical Engineering, Mississippi State University, Mississippi State, MS 39762, USA

${ }^{c}$ Mississippi State Chemical Laboratory, Mississippi State University, Mississippi State, MS 39762, USA

${ }^{\mathrm{d}}$ Faculty of Science, , University of Ruhuna, Matara, Sri Lanka

†Deceased

*Corresponding author: (M. G. White) Dave C. Swalm School of Chemical Engineering, Mississippi State University, Mississippi State, MS 39762, USA white@che.msstate.edu

\section{Graphical Abstract}

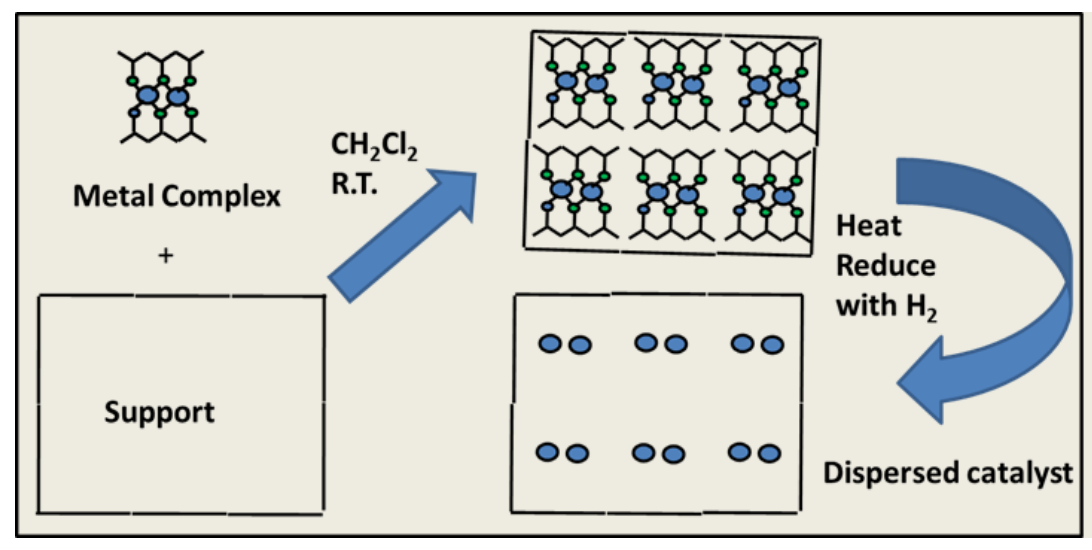

